\title{
INDEKS DAUN Sonneratia alba PADA ZONA TUMBUH BERBEDA DI PESISIR DESA TIWOHO KABUPATEN MINAHASA UTARA
}

\author{
(Leaf Index of Sonneratia alba Growing on Different Zones at Tiwoho Village Coast of \\ North Minahasa Regency)
}

Dedi Buamona $^{{ }^{\star}}$, Rignolda Djamaluddin ${ }^{1}$, Agung B. Windarto ${ }^{1}$

1. Program Studi IImu Kelautan, Fakultas Perikanan dan IImu Kelautan, Universitas Sam Ratulangi, Manado.

e-mail : buamonad@yahoo.com

The mangrove ecosystem occurs on coastal regions especially on the environments affected by tide. This ecosystem is dominated by species of trees and shrubs that are capable to grow on saline and brackish environments. In this research, leaves of Sonneratia alba were collected from three different locations at mangrove of Tiwoho Village. The three locations were coastal zone, middle zone and landward zone. Based on morphometric measurement of leaves of $S$. alba, it was found that the diversity coefficient was $75,76 \%$ at coastal zone, $68,03 \%$ at middle zone, and $63,29 \%$ at landward zone. This result indicated that there might be differences in trees adaptation and competition among three different zones. Result of t-test on average values of width and length of leaves of $S$. alba indicated that these two morphometric variables were significantly different in general. The trend was that width of leaves tended to increase toward the landward zone with the average value of $115,34 \mathrm{~mm}$ on the landward zone. Besides, the bigger average value of leaves' length was $79,54 \mathrm{~mm}$ at middle zone. Result of ttest on average values of leave index indicated that there were significant different between the middle zone and the landward zone. These were not significant between the coastal zone and middle zone, and between the coastal zone and the landward zone.

Keywords: Sonneratia alba, Leaf Index, Coastal, Tiwoho Village

Ekosistem mangrove terdapat di wilayah pesisir khususnya pada lingkungan yang dipengaruhi oleh pasang surut. Ekosistem ini didominasi oleh spesis pohon dan semak yang mampu tumbuh di perairan asin dan payau. Sampel daun Sonneratia alba dikumpulkan dari tiga lokasi berbeda pada mangrove di Desa Tiwoho yang meliputi zona sebelah laut, zona tengah dan zona dekat daratan. Berdasarkan hasil pengukuran morfometrik daun $S$. alba di Desa Tiwoho diperoleh nilai koefisien keragaman morfometrik daun pada zona sebelah laut sebesar $75,76 \%$, zona tengah $68,03 \%$ dan zona dekat daratan sebesar $63,29 \%$. Hal ini mengindikasikan adanya perbedaan dalam hal adaptasi dan kompetisi di masing-masing zona. Hasil uji-t terhadap nilai rata-rata lebar dan panjang daun mengindikasikan bahwa secara umum lebar dan panjang daun berbeda secara signifikan. Kecenderungan yang ada bahwa ukuran lebar daun semakin membesar ke arah darat dengan nilai rata-rata di zona dekat daratan sebesar 115, $34 \mathrm{~mm}$. Sedangkan ukuran panjang daun terbesar ditemukan di zona tengah dengan nilai rata-rata sebesar $79,54 \mathrm{~mm}$. Hasil uji-t nilai rata-rata indeks daun pada ketiga lokasi menunjukkan bahwa terdapat perbedaan yang signifikan antara zona tengah dan zona dekat daratan. Antara zona sebelah laut dan zona tengah serta zona sebelah laut dan dan zona dekat daratan tidak terdapat perbedaan yang nyata.

Kata Kunci : Sonnaratia alba, Indeks Daun, Pesisir, Desa Tiwoho

\section{PENDAHULUAN}

Menurut Undang-Undang No. 41 Tahun 1999 tentang Kehutanan, hutan adalah suatu kesatuan ekosistem berupa hamparan lahan berisi sumber daya alam hayati yang didominasi pepohonan dalam persekutan alam lingkungannya, yang satu dengan lainnya tidak dapat dipisahkan. Sedangkan arti kata mangrove adalah vegetasi hutan yang tumbuh diantara 
garis pasang surut, tetapi juga dapat tumbuh pada pantai karang, pada dataran koral mati di atasnya ditimbuni selapis tipis pasir atau ditimbuni lumpur atau pantai berlumpur (Saparinto, 2007).

Hutan mangrove adalah tipe hutan yang khas yang terdapat disepanjang pantai atau muara sungai yang dipengaruhi oleh pasang surut air laut (Nontji, 1987 dalam Rahadyan, 2003). Segala tumbuhan yang terdapat didalam ekosistem hutan mangrove saling berinteraksi dengan lingkungannya, baik yang bersifat abiotik maupun biotik. Hutan mangrove merupakan ekosistem yang unik dan berfungsi ganda dalam lingkungan hidup. Hal ini disebabkan oleh adanya pengaruh lautan dan daratan, sehingga terjadi interaksi kompleks antara sifat fisika, sifat kimia, dan sifat biologi (Arief, 2003).

Hutan mangrove Tiwoho merupakan Wilayah zona rimba kawasan konservasi Taman Nasional Bunaken (TNB), dimana dalam pengelolaannya daerah ini termasuk bagian dari seksi pengelolaan Taman Nasional (SPTN) wilayah konservasi bertepatan dengan penetapatan TNB berdasarkan surat keputusan menteri kehutanan Nomor : 730/KPTS-II/1991 tanggal 15 Oktober 1991. Kawasan mangrove ini berada di sepanjang pesisir bagian utara Molas (Kota Manado) dan Wori (Kab. Minahasa Utara). Luas keseluruhan mangrove TNB di wilayah ini seluas 192,86 ha atau sebesar $7,27 \%$ dari luas total hutan mangrove di Sulawesi Utara (Halidah dan Kama, 2013). Selain itu kawasan ini juga berfungsi sebagai perlindungan keanekaragaman hayati khususnya afifauna dalam hal daya dukung habitat.

Bagi masyarakat Tiwoho keberdayaan mangrove sangat bermanfaat terhadap keberlangsungan hidupnya, sebab kawasan ini menjadi sumber ekonomi dan penyangga bagi pemukiman mereka terhadapa dampak negatif dari air laut. Mangrove Tiwoho memiliki luas 62,72 ha atau sekitar $11,2 \%$ dari 556,485 ha luas wilayah desa Tiwoho (Pontoh, 2011). sejak duluh masyarakat telah terbiasa secara rutin dan turun temurun memanfaatkan hutan mangrove sebagai sumber penghidupan. Masyarakat menggunakan mangrove sebagai kawasan berburu, tempat memenuhi kebutuhan rumah tangga dan keperluan kesehatan. Kegiatan yang rutin dilakukan yaitu mencari ikan, kepiting, biak (kerang laut), soa-soa (biawak), burung, mencari kayu bakar, tiang rumah, bahan baku pembuatan atap rumah, sumber pakan ternak dan obat-obatan tradisional (Sonjaya, 2007). Sonneratia alba adalah salah satu jenis pohon yang hidup di hutan mangrove. Jenis yang merupakan famili dari Sonneratiaceae ini memiliki nama daerah antara lain pedada, perepat, pidada, bogem, bidada, posi - posi, wahat, putih, berapak, bangka, susup, kedada, muntu, pupat dan mange mange. Namun masyarakat di sekitar Taman Nasional Baluran mengenalnya dengan sebutan Pedada. (Anonim, 2017). Penelitian ini dirancang dengan tujuan mengukur dan menganalisis indeks daun $S$. alba pada zona tumbuh berbeda di pesisir pantai Desa Tiwoho Kabupaten Minahasa Utara.

\section{METODE PENELITIAN}

Peneltian ini dilaksanakan selama tiga bulan dengan lama waktu pengambilan data dan analisis selama 1 bulan. Lokasi yang di pilih sebagai tempat pelaksanaan penelitian yaitu pesisir Desa Tiwoho Kecamatan Wori Kabupaten Minahasa Utara. Peta lokasi penelitian dapat dilihat pada (Gambar 1).

Titik sampling dipilih wewakili tiga lokasi atau habitat tumbuh tegakan $S$. alba yaitu bagian depan dekat laut bagian tengah dan belakang (dekat darata). Pada masing-masing habitat tumbuh ditetapkan 3 sub-lokasi sampling (ulangan). 


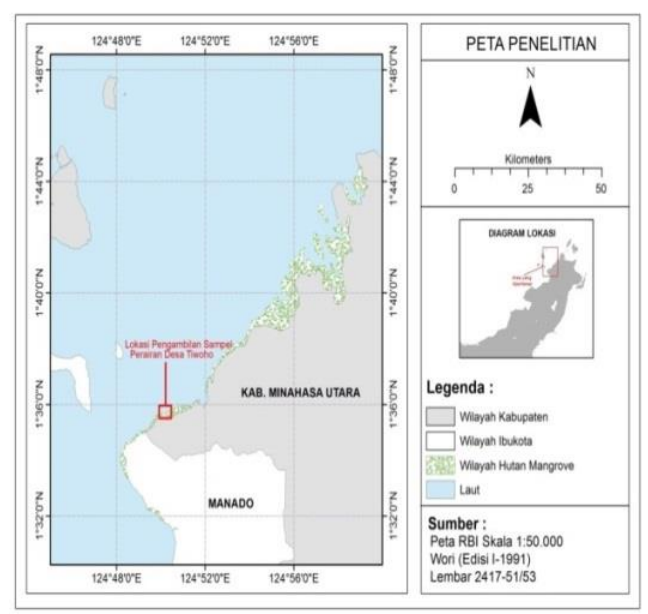

Gambar 1. Peta lokasi peneltian

\section{HASIL PENELITIAN}

Sampel daun mangrove spesis S. alba diperoleh dari desa Tiwoho Kabupaten Minahasa Utara, pada tiga lokasi berbeda (zona dekat laut, zona tengah dan zona dekat daratan). Kondisi lokasi sampling secara umum; memiliki substrat berpasir, landau, dengan banyak perakaran pneumatofor yang pendek.

Kondisi kesehatan tegakan dapat diketahui berdasarkan morfometrik daun. Secara visual pada Gambar 1, 2, dan 3 ditampilkan grafik distribusi log normal, populasi $S$. alba di desa Tiwoho untuk ketiga lokasi sampling.

Nilai Koefisien keragaman (CV) morfometrik daun di zona pantai (dekat laut) adalah sebesar $75,76 \%$, di zona tengah sebesar $68,03 \%$ dan di darat sebesar 63,29\%. Hal tersebut menunjukkan nilai-nilai morfometrik daun yang lebih memencar dari mangrove yang tumbuh di pantai. Berdasarkan pemencaran tersebut, maka diketahui populasi $S$. alba di pantai mempunyai daya adaptasi yang lebih luas dalam menghadapi kondisi lingkungan serta komposisi antar individu yang rendah jika dibandingkan dengan populasi $S$. alba di darat. Sedangkan nilai koefisian keragaman morfometrik daun di zona tengah lebih rendah dari morfometrik daun di pantai dan lebih tinggi lebih dari morfometrik di zona dekat daratan Berdasarkan hasil analisis morfometrik diperoleh nilai daun di zona pantai bervariasi antara 0,05 hingga 26,73 , di zona tengah antara 0,87 hingga 2,44 , dan di zona dekat daratan antara antara 0,59 hingga 2,69. Hasil yang diperoleh menunjukkan terdapat kecenderungan perubahan pertumbuhan daun, dimana lebar daun semakin membesar ke arah darat (daun cenderung membulat), ukuran panjang daun semakin kecil. Lebih jauh dapat dijelaskan bahwa perubahan kesimetrian daun yang semakin memendek atau membulat mengidentifikasikan bahwa populasi mangrove di desa Tiwoho dalam keadaan kurang sehat.

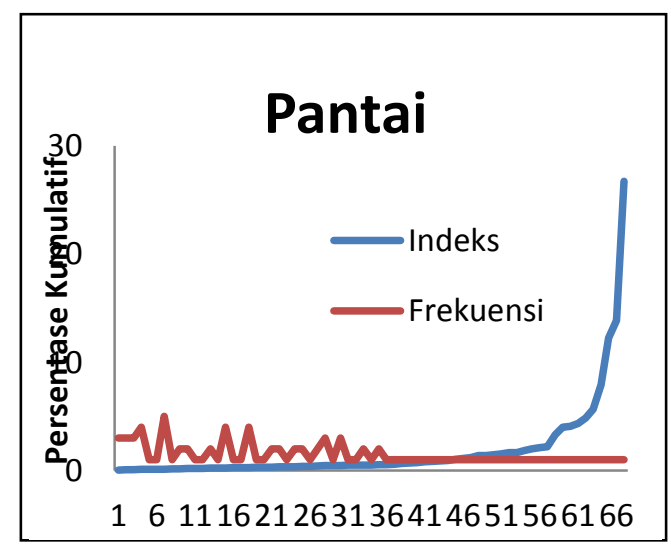

Gambar 2. Distribusi log normal morfometrik daun $S$. alba di zona pantai (dekat laut).

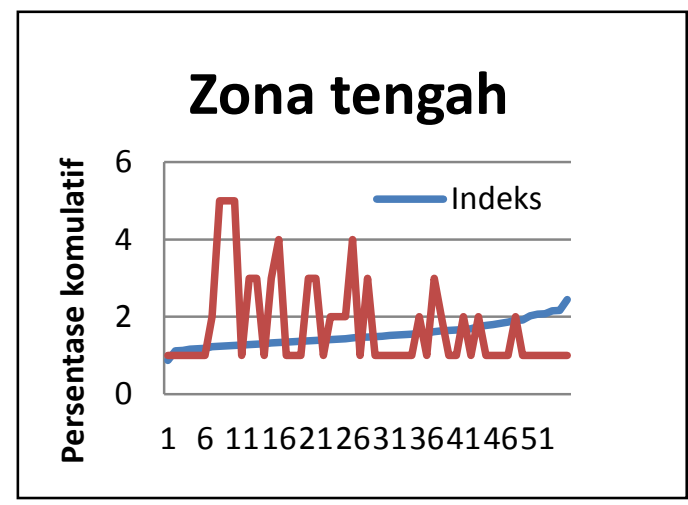

Gambar 3. Distribusi log normal morfomotrik daun Sonneratia alba di zona tengah 


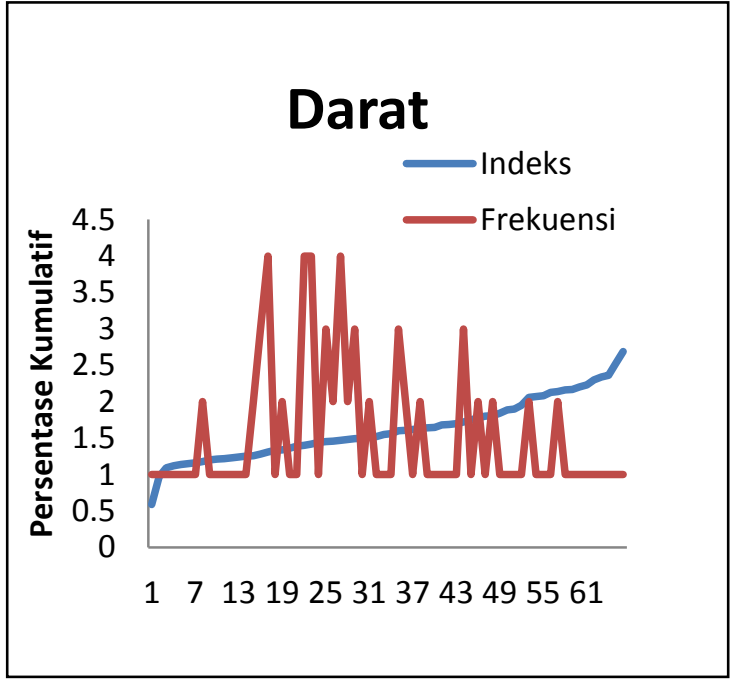

Gambar 4. Distribusi log normal morfometrik daun $S$. alba di zona dekat daratan.

\section{Hasil uji-t}

Berdasarkan hasil Uji-t di peroleh bahwa perbandingan ukuran rata-rata lebar dan panjang daun $S$. alba pada setiap lokasi tumbuh.

Tabel 1. Hasil uji-t.

\begin{tabular}{|c|c|c|c|}
\hline Variabel & Hasi Uji t & $\begin{array}{c}\text { Nilai } \\
\text { rataan }\end{array}$ & $\begin{array}{l}\text { Standar } \\
\text { Deviasi }\end{array}$ \\
\hline L1: L2 & Signifikan & $\begin{array}{c}L 1=15,04 \\
L 2=113,92\end{array}$ & $\begin{array}{l}\mathrm{L} 1=12,48 \\
\mathrm{~L} 2=10,85\end{array}$ \\
\hline L1: L3 & Signifikan & $\begin{array}{c}L 1=15,04 \\
L 3=115,34\end{array}$ & $\begin{array}{l}\mathrm{L} 1=12,48 \\
\mathrm{~L} 3=17,60\end{array}$ \\
\hline L2: L3 & $\begin{array}{c}\text { Tidak } \\
\text { Signifikan }\end{array}$ & $\begin{array}{l}L 2=113,91 \\
L 3=115,34\end{array}$ & $\begin{array}{l}\mathrm{L} 2=10,85 \\
\mathrm{~L} 3=17,60\end{array}$ \\
\hline P1: P2 & Signifikan & $\begin{array}{l}P 1=32,55 \\
P 2=79,54\end{array}$ & $\begin{array}{l}P 1=20,29 \\
P 2=14,11\end{array}$ \\
\hline $\mathrm{P} 1: \mathrm{P3}$ & Signifikan & $\begin{array}{l}\mathrm{P} 1=32,55 \\
\mathrm{P} 3=74,94\end{array}$ & $\begin{array}{l}P 1=20,29 \\
P 3=12,30\end{array}$ \\
\hline P2: P3 & Signifikan & $\begin{array}{l}P 2=79,54 \\
P 3=74,94\end{array}$ & $\begin{array}{l}P 2=14,11 \\
P 3=12,30\end{array}$ \\
\hline
\end{tabular}

Keterangan: P1 (panjang daun di zona pantai ), P2 ( panjang daun di zona tengah), P3 (panjang daun di zona dekat daratan), L1 (lebar daun di zona pantai), L2 (lebar daun di zona tengah), L3 (lebar daun di zona dekat daratan)
Nampak berbeda signifikan. Secara umum, hanya ada satu perbandingan ukuran rata-rata lebar daun yang tidak signifikan yaitu antara lebar daun pada lokasi tumbuh zona tengah dan lokasi tumbuh sebelah daratan. Ringkasan hasil uji-t dapat dilihat pada (Tabel 1).

Hasil uji-t terhadap nilai rata-rata indeks daun $S$. alba menujukkan bahwa antara zona tengah dan zona sebelah daratan terdapat perbedaan yang nyata. Sementara itu, antara zona pantai dan zona tengah dan antara zona pantai dan zona dekat daratan tidak terdapat perbedaan yang nyata.

\section{KESIMPULAN}

Koefisien

keragaman morfometrik daun $S$. alba di desa Tiwoho diperoleh nilai koefisien keragaman morfometrik daun sebesar $75,76 \%$ pada zona pantai, sebesar $68,03 \%$ pada zona tengah dan sebesar $63,29 \%$ pada zona dekat daratan. Hasil ini menunjukkan adanya perbedaaan adaptasi dan kompetisi di ketiga zona tersebut.

Secara umum, hasil uji-t ukuran rata-rata lebar dan panjang daun menunjukkan adanya perbedaan yang signifikan. Kecenderungan yang ditemukan adalah bahwa ukuran lebar daun semakin membesar ke arah daratan. Hasil uji-t nilai rata-rata indeks daun menujukkan bahwa antara zona tengah dan zona daratan terdapat perbedaan yang signifikan, sedangkan antara zona pantai dan tengan serta antara zona pantai dan zona dekat daratan tidak terdapat perbedaan yang signifikan.

\section{DAFTAR PUSTAKA}

Anonim, 2017. Konservasi. Laut. Blogspot. co.id/2011/08/ mangrove-Sonneratia-alba.html. Di unduh pada 15 Januari 2016 pukul 09.00 Wita. 
Arief, A. 2003. Hutan mangrove fungsi dan manfaatnya. Yogyakarta: kanisius,2003. p 47.

Halidah dan Kama. H. 2013. Penyebaran alami Avicennia marina (Forsk) vierh dan Sonneraia alba smith pada subsrat pasir. Indonesia forest rehabilitation journal 1(1): 51-58 pp.

Nontji, A.. 1987 . Laut Nusantara. Jakarta: Djambatan. Jakarta. Indonesia. p 146.

Saparinto, C. 2007. Pendayagunaan Ekosistem Mangrove. Penerbit Dahara Prize. Semarang. p 236.

Sonjaya, J.A 2007. Kebijakan untuk mangrove : Mengkaji kasus dan merumuskan kebijakan Internasional Union For Concervation of Nature and Nature Resour dan mangrove Action Project. IUCN Publications Servicet Union. Yogyakarta.

Pontoh, O. 2011. Peranan Nelayan terhadap rehabilitasi ekosistem mangrove. Jurnal Perikanan dan Kelautan Tropis 7(2) :73-79. 